\title{
A Mathematical Model of Customer Satisfaction depending on technical Design Parameters in the context of Product Generation Engineering
}

\author{
Günseli Aksoy', Tobias Huth², Thomas Vietor ${ }^{2}$ \\ ${ }^{1}$ Volkswagen AG, Germany \\ guenseli.aksoy@volkswagen.de \\ ${ }^{2}$ Institute for Engineering Design, TU Braunschweig, Germany \\ tobias.huth@tu-braunschweig.de \\ ${ }^{2}$ Institute for Engineering Design, TU Braunschweig, Germany \\ t.vietor@tu-braunschweig.de
}

\begin{abstract}
Many manufacturers use customer research instruments, such as empirical surveys in order to find out their needs to consider in new products to improve customer satisfaction. However, the systematic of how the customer satisfaction due to the evaluation of customer feedback is used, particularly up to a design parameter level of product structure, is not considered by any approach. In this contribution, an approach is carried out to show the overall customer satisfaction by application of a mathematical model with regard to the scope of the Product Generation Engineering.
\end{abstract}

Keywords: Engineering Design, Customer Integration Methods, Integrated Product Development

\section{Introduction and state of the art}

Many manufacturers use customer research instruments, such as empirical surveys or online based websites for evaluation of customer feedback in order to find relevant customer needs to consider in new products (Schütte et al., 2008). Ideally developers can integrate this information into the design process as early as possible (Yagci et al., 2018). This kind of product development information of existing products are used for the next product generation and integrated into the product development process.

The existing products are considered as reference products in the scope of Product Generation Engineering (PGE) by the studies of Albers et al. (Albers, Haug et al., 2018). They show in their work that products are developed through the systematic variation of technical subsystems (for e.g. components, functions, design parameters) over product generations, which they support in the description of the product model in the context of PGE (Albers, Bursac et. al, 2015) (Albers, Haug et al., 2018). PGE model considers on one hand reference products while developing the new product generation. This kind of development is based on at least one 
reference product. In that case, for e.g. previous generations or existing subsystems can be relevant for the chosen reference product for the development activity. On the other hand each development is individualized by a systematic combination of the development activities (Albers, Haug et al., 2018). In several studies of PGE, different focuses have been considered such as handling large number of influence factors that can impact customer satisfaction (Albers, Dumitrescu et al., 2018). Additional some focuses are the integration of customer benefits in the early phase of product development process (Albers, Basedow et al., 2018), the impact of variations in design engineering activities on subsystems (Albers, Eichhorn et al., 2018) and supporting the relation between technical subsystems and customer benefits (Albers, Haug et al., 2018). PGE approaches have shown that customer feedback evaluation and integration in the product development process are missing.

The consideration of product development information of existing products and their integration in the early phase of product development can ensure the customer satisfaction. For that, anonym customer feedback from open or close questionnaires of empirical surveys of existing products could be evaluated. While close questionnaires result in well-defined customer feedback by predetermined answers, open questionnaires, as the common industry standard, provide more creative and free environment for the customer. Due to the unstructured nature of qualitative customer feedback, it is laborious to extract product development information from open questionnaires. Considering this statement, many methods have been used, for e.g. by identifying causes of problems (Ishikawa, 1993) or affective declaration (on Kansei Engineering) (Schütte, 2005) (Rai, 2012) as well as verbs, adjectives, etc. to link them to the technical parameters. In addition, considering word count by deep learning (Wang et al., 2018) and key words identification to map them to product features from online reviews (Park et al., 2018), as well as addressing affective declarations to product features by text mining utilizing online reviews (Wang, Li et al., 2018) are relevant. Furthermore Quality Function Deployment (QFD), which focuses on translation of customer needs into the technical requirements, is widely used (Herrmann et al., 2011) (Urban et al., 1993) (Schulte, 2006). However, for a big amount of customer data, QFD could be complex (Nehuis, 2014). None of these approaches above consider PGE while development activities.

Other approaches for providing customer satisfaction are defined with different focuses. For example, the approach of Schulte is based on semantic mapping of customer feedback on the product structure (Schulte, 2006). Chen \& Chen define customer satisfaction function based on importance weight of design requirements (Chen et al., 2014). On the other hand, Li et al. determine customer satisfaction by rating engineering characteristics using a probabilistic language method (Li et al., 2019). Neither (Schulte, 2006), (Chen et al., 2014) nor (Li et al., 2019) consider PGE while development activities.

A holistic approach that includes the evaluation of big amount of customer feedback, their mapping into the detailed level of technical subsytems and the determination of the importance of these subsystems is necessary in the automotive industrie.

\section{Research Goal and Methodology}

The aim of this contribution is to link the qualitative customer feedback with the technical subsystems of design parameter and to define the importance weight of these parameters in the context of PGE. Thereby customer satisfaction with the product can be ensured.

In order to reach the research goal, the structure of Design Research Methodology (Blessing et al., 2009) is used by answering as next the following Research Questions:

- How is the handling of complexity during the evaluation of imprecise customer feedback and how can it be supported by introduced approaches above?

- How can Customer Requirements be derived from evaluated customer feedback? 
- How can the relation between customer feedback and subsystems up to the design parameter level be shown considering the importance weight of each design parameter?

- How is it possible to consider the desired approach as a product model in the context of PGE?

The Desriptive Study I (Understanding) is first carried out, in which the customer feedback are determined from empirical surveys based on existing products in the automotive industry. Also qualitative customer feedback evaluation and its impact on technical data are studied. In the Prescriptive Study (Support) the product development relevant information from customer feedback is determined considering different types of categories. On one hand the focus lies on the clustering the evaluated customer feedback in product components, functions and subsequently in design parameters. These activities are considered in the context of PGE. In this case PGE model is completed up to the design parameter level. On the other hand, the determination of the importance weights of technical design parameters by using a mathematical model of customer satisfaction is another focus for support. Finally, in the Descriptive Study II (Evaluation) customer feedback evaluation is carried out and the importance weight of each technical design parameters are calculated. The present contribution closes by depicting a discussion of findings and gives an outlook on follow-up research.

\section{Approach for correlation between technical design parameter and customer feedback in the context of PGE}

In this section the approach is introduced by answering the scientific questions above. The product model by Albers, Bursac, Fahl et al. (2018) is carried out from solution-open (concretization) to solution-specific-description (abstraction). It supports the analysis of specific information from reference products. In this study, this model is completed to the next concrete subsystem level, Design Parameters (DP) for each Function (F) and Component (B) (For e.g. diameter or depth are DP for the product component cup holder).

This completed model (M) shows the relation between customer feedback of empirical surveys up to the technical subsystem DP. To achieve this target, customer feedback $\left(\mathrm{FB}_{1}, \mathrm{FB}_{2}, \ldots, \mathrm{FB}_{\mathrm{f}}\right)$ are first evaluated with the help of categorization (Categories $\mathrm{C} 1, \mathrm{C} 2, \ldots$ ). An example of categorization of feedback 1 is depicted on the left lower corner of Figure 1. The customer feedback are clustered into defined conception factors $\left(\mathrm{CF}_{1}, \mathrm{CF}_{2}, \ldots, \mathrm{CF}_{\mathrm{x}}\right)$ and sub-conception factors $\left(\mathrm{S}-\mathrm{CF}_{1}, \mathrm{~S}-\mathrm{CF}_{2}, \ldots, \mathrm{S}-\mathrm{CF}_{\mathrm{y}}\right)$ in order to differentiate the customer feedback themes. Afterwards, in the synthesis the customer Requirements $\left(\mathrm{CR}_{1}, \mathrm{CR}_{2}, \ldots, \mathrm{CR}_{\mathrm{m}}\right)$ are elicitated considering the categorized information and splitted in subsystem functions $\left(F_{1}, F_{2}, \ldots, F_{n}\right)$ and subsystem components $\left(\mathrm{B}_{1}, \mathrm{~B}_{2}, \ldots, \mathrm{B}_{\mathrm{z}}\right)$, subsequently, in subsystem design parameters of $\mathrm{F}_{\mathrm{j}}\left(\mathrm{DP}_{1}\right.$, $\left.\mathrm{DP}_{2}, \ldots, \mathrm{DP}_{\mathrm{p}}\right)$ and $\mathrm{B}_{\mathrm{g}}\left(\mathrm{DP}_{1}, \mathrm{DP}_{2}, \ldots, \mathrm{DP}_{\mathrm{q}}\right)$ based on product structure.

Considering the model M below, Chen \& Chen`s mathematical model (Chen et al., 2014) is then enhanced to the next subsystem level of DP in order to show the impact of each relevant DP on the customer satisfaction with the product. This occurs by defining the importance weight of each DP. 


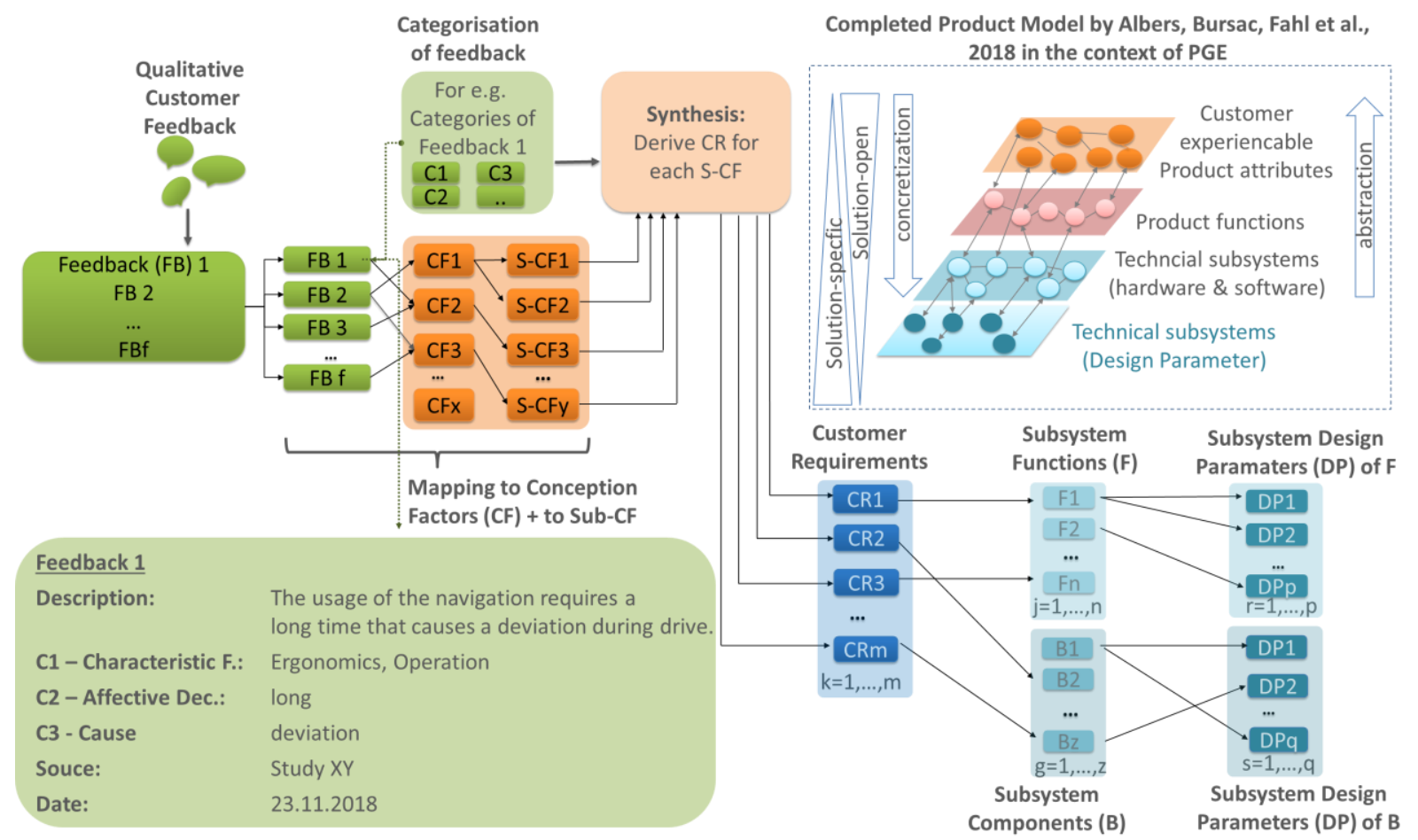

Figure 1. Research Approach with the completed product model M

\subsection{Evaluation of Customer Feedback}

Qualitative customer feedback are taken from an empirical study that is provided from a specific company and contains many themes, which are investigated for planty of products. One of these themes is the „customer satisfaction with the product" that is relevant for the customer feedback evaluation in this work. The customer feedback are based on close and open questionnaires. As mentioned in section 1, close questionnaires result in well-defined customer feedback by predetermined answers. The possible close questions would be for e.g. „Please evaluate your whole product satisfaction considering the scale 1 to $10^{\text {“ }}$ or „How would you rate your steering wheel considering the scale 1 to $10^{\text {". }}$. Qualitative customer feedback are based on open questionnaires in order to give customers the possibility to evaluate their products independent of conceretely created questions. These kinds of questions are for e.g. „What do you particulary like or dislike about your new car?“ and a possible answer of customers would be for e.g. „I can not see the clock, unless the radio is on". There are also superficial types of customer feedback, which are difficult to interpret and transfer into the technical subsystems. An example for these kind of feedback is „I am not satisfied with the view of my car", where the customer does not give a concrete information about the type of the view (for e.g. rear view, side view, etc.). Also the feedback „I do not like the steering wheel because it is not cool“ will also be clustered as a superficial feedback because of the identification difficulty of a concerete information for any technical subsystem.

By evaluating customer feedback, different statements of customers for a specific technical subsystem are collected in order to define diverse categories of different types of information. In addition, conception factors are determined for the distinction of different customer requirement themes. The structure of conceptions factors and mapping to components and functions is defined once for each individual product (e.g. Vehicle, Bicycle, etc.). The conception factors may need to be updated, if new features are implemented within the product, e.g. new driver assistance system. 


\section{Categories:}

Every qualitative customer feedback can be seen as an amount of unstructured information. To facilitate the access to the enclosed information every feedback needs to be categorized. For the definition of categories, existing approaches (Schütte, 2005) (Urban et al., 1993) (Nehuis, 2014) (Ishikawa, 1993), discussions with specialists, and the content of qualitative customer feedback from empirical surveys are considered:

Type of characteristic feature: The list of Characteristic Feature in Design Engineering by Pahl/Beitz (2007) supports the determination of technical requirements of a product component. This list can be used to categorize customer feedback in relation to the kind of the enclosed information within the feedback, such as geometrical information (Example: Dimension of Cup Holder), ergonomic information (Example: Usage of Cup Holder), etc.

Affective Declaration: The analysis of affective customer opinions (e.g.. nice, long, hard, etc.) of products has become increasingly important in the industrial practice. Affect is said to be customer`s psychological response to the products properties (Halender et al., 2012).

Function-Related Statement: This category helps to derive abstract information, which is function oriented.

Extra Statement: With this category is provided to derive information that can be seen as extra information. The analysis of customer feedback from the empirical surveys has shown that the customers express these kind of information. Colloquial statements from customers can be related to extra statement.

Cause: This category supports deriving the reasons of the mentioned problem that causes the customers dissatisfaction with the product or parts of it. This can be done with the help of the W-Questions in Design Engineering (Nehuis, 2014) and Ishikawa Diagram (Identifying the problem considering the adventitious causes) (Ishikawa, 1993).

Comparison to Competitor/Comparison with previous product: The analysis of the qualitative customer feedback from empirical surveys has shown that they include much information, such as comparison with other products or with the previous product. With the help of this category it is possible to derive competitor information.

Superficial: Qualitative feedback includes the information that is not well or detailed described.

One of the major advantages of using the categories is that they ensure to differentiate and to filter several kind of product development relevant information. For e.g., if the developers need to focus on competitive data from customer feedback of a specific product, they can easily find out the needed information within the appropriate category.

Ideally, all of these categories can be attributed to each feedback regardless of the cultural differences of the developer, different education, and also the individual background of the subject matter, in order to achieve a homogeneous evaluation perspective.

\section{Conception Factors}

The conception factors (CF) have been introduced by Nehuis (2014) for defining products (e.g. a vehicle) in a generic manner under consideration of customer related characteristics, properties and features of the respective product. The characteristics of a product help for instance to define the design, such as definition of spatial arrangement of components, while the properties support the description of the behaviour of a product (Vajna et al., 2009). These factors support the description a vehicle as neutrally as possible and are derived from vehicle fields such as chassis, package, etc. (Nehuis, 2014). In this approach, the usage of such factors is enhanced by clustering similar $\mathrm{CF}$ into superordinate factors, such as driving assistance 
systems, ergonomie, etc., which can be relevant for customer satisfaction. The usage of these factors support to generate a more detailed vehicle concept (Nehuis, 2014).

$\mathrm{CF}$ are utilized in this present publication to differentiate the customer feedback themes. From these factors, sub-CF are derived, in order to provide more detailed requirement themes. It is possible to link one customer feedback during evaluation to more than one $\mathrm{CF}$ and sub-CF as depicted in Figure 1. For their determination, the main problem has to be identified in order to relate relevant feedback to the correct $\mathrm{CF}$ and sub-CF. The $\mathrm{CF}$ are accepted as the customer experiencable product attributes of product model by Albers et al. (2018).

\subsection{Mathematical Model of the Approach}

The development of new products requires the determination of the product quality by the Research \& Development (R\&D) team for achieving satisfaction degree of the target customers, for e.g. of a specific market (Chen et al., 2014). Chen \& Chen emphasize in their work that the existing literature focuses on the determination of optimal solutions of design requirements (based on CR) for maximizing customer satisfaction considering the budgetary limitation. However, achieving the level of desired customer satisfaction in terms of product quality is ignored (Chen et al., 2014). Consequently, the determined quality level of new products may not match CR. The term quality is defined as an objective characteristic of a product, which is measurable and comparable (Muffato et al., 1995). According to DIN EN ISO 9000 (DIN EN ISO 9000, 2015), the quality is defined as the level, in which a set of inherent characteristics of an object meets defined requirements.

Considering these above statements, a function relating the achieved customer satisfaction level of a specific product to the design parameter (DP) has to be determined.

\subsubsection{Normalized relational intensity between Customer Requirements, Functions/Components and Design Parameters}

In the present publication, the normalized relational intensity $\left(\mathrm{R}_{\mathrm{ij}}^{\text {norm }}\right)$ (1) between $\mathrm{CR}$ and functions of product $(F)$ using the Correlations $\left(\gamma_{\mathrm{kj}}\right)$ between Fs, and normalized relational intensity $\left(\mathrm{R}_{\mathrm{ig}}^{\text {norm }}\right)(2)$ between $\mathrm{CR}$ and product components $(\mathrm{B})$ using correlations $\left(\varphi_{\mathrm{kg}}\right)$ between Bs are defined as an analogy to the normalized relational intensity between $\mathrm{CR}$ and design requirements of Chen \& Chen. This is redefined under the consideration of the lack of Wasserman's normalization model (Chen et al., 2014). Furthermore, as Chen \& Chen emphasize it, the possibility of correlation $\left(\beta_{\mathrm{il}}\right)$ between CRs is also used in a normalization model (3) by determining the normalized weights $\left(d_{i}^{\text {norm }}\right)$ of CRs.

$$
\mathrm{R}_{\mathrm{ij}}^{\mathrm{norm}}=\frac{\left(\sum_{\mathrm{k}=1}^{\mathrm{n}} \gamma_{\mathrm{kj}}\right) \mathrm{R}_{\mathrm{ij}}}{\sum_{\mathrm{j}=1}^{\mathrm{n}}\left(\sum_{\mathrm{k}=1}^{\mathrm{n}} \gamma_{\mathrm{kj}}\right) \mathrm{R}_{\mathrm{ij}}}(1), \mathrm{R}_{\mathrm{ig}}^{\mathrm{norm}}=\frac{\left(\sum_{\mathrm{k}=1}^{\mathrm{z}} \varphi_{\mathrm{kg}}\right) \mathrm{R}_{\mathrm{ig}}}{\sum_{\mathrm{g}=1}^{\mathrm{z}}\left(\sum_{\mathrm{k}=1}^{\mathrm{z}} \varphi_{\mathrm{kg}}\right) \mathrm{R}_{\mathrm{ig}}}(2), \mathrm{d}_{\mathrm{i}}^{\text {norm }}=\frac{\left(\sum_{\mathrm{l}=1}^{\mathrm{m}} \beta_{\mathrm{il}}\right) \mathrm{d}_{\mathrm{i}}}{\sum_{\mathrm{i}=1}^{\mathrm{m}}\left(\sum_{\mathrm{l}=1}^{\mathrm{m}} \beta_{\mathrm{il}}\right) \mathrm{d}_{\mathrm{i}}}(3)
$$

Normally, developers have their own models, where they verify their specific CR for relevant $\mathrm{F}$ and $\mathrm{B}$ and the possible correlations within $\mathrm{F}$ and $\mathrm{B}$ respectively. The need of this kind of correlations is a trivial option, as proved by Chen \& Chen`s study (Chen et al., 2014).

For each $\mathrm{F}$ and $\mathrm{B}$ there is one or several design parameters which leads to more concretization. A new relational intensity between F and DP ( $\left.D_{j r}^{\text {norm }}\right)(4)$ as well as between B and DP $\left(D_{\mathrm{gs}}^{\text {norm }}\right)$ (5) are defined. This is carried out in the most concrete level of technical subsystems of a product model in the context of PGE ( $\mu_{k r}$ and $\mu_{k s}$ correlations within DPs).

$$
\mathrm{D}_{\mathrm{jr}}^{\text {norm }}=\frac{\left(\sum_{\mathrm{k}=1}^{\mathrm{p}} \mu_{\mathrm{kr}}\right) \mathrm{D}_{\mathrm{jr}}}{\sum_{\mathrm{r}=1}^{\mathrm{p}}\left(\sum_{\mathrm{k}=1}^{\mathrm{p}} \mu_{\mathrm{kr}}\right) \mathrm{D}_{\mathrm{jr}}}(4), \mathrm{D}_{\mathrm{gs}}^{\mathrm{norm}}=\frac{\left(\sum_{\mathrm{k}=1}^{\mathrm{q}} \mu_{\mathrm{ks}}\right) \mathrm{D}_{\mathrm{gs}}}{\sum_{\mathrm{s}=1}^{\mathrm{q}}\left(\sum_{\mathrm{k}=1}^{\mathrm{q}} \mu_{\mathrm{ks}}\right) \mathrm{D}_{\mathrm{gs}}}
$$


Considering the goal of this present publication, the next necessary step is to define the normalized relational intensity between $\mathrm{CR}$ and design parameter. The normalized relational intensity between CR and F, B are depicted in (1) and (2) and also the identical intensity between F, B and design parameter is shown in (4) and (5).

\subsubsection{Customer satisfaction function considering quality level of a product}

Stechmann (Stechmann, 2011) emphasizes in her work that the fullfillment of customer requirements of a specific product does not mean unconditionally ensuring the customer satisfaction. Product quality should also be understood and considered, in order to verify the customer satisfaction with the relevant product. Hence, the fullfillment of product quality level can increase the customer satisfaction.

The study of Chen \& Chen shows that customer satisfaction $\mathrm{CS}(\mathrm{X})$ is related to the product design quality $\mathrm{DQ}(\mathrm{X})$ positively in terms of a concave down function $\mathrm{CS}_{\mathrm{F}, \mathrm{B}}(\mathrm{X})=\left[\mathrm{DQ}_{\mathrm{F}, \mathrm{B}}(\mathrm{X})\right]^{1 / \mathrm{k}}$ (6), where $X$ is the vector that contains the fullfillment levels of all Fs and Bs. It can be depicted as $X_{F}$ for $F=\left[x_{1}, x_{2}, \ldots, x_{n}\right]$ and $X_{B}$ for $B=\left[x_{n+1}, \ldots ., x_{z}\right]$. This function is carried out, so that in the early phase of product development process the developed product will be perceived by the target customers of a chosen market. It describes the fact that the marginal effect of customer satisfaction declines while product design quality increases (Chen et al., 2014). The characteristic parameter $\mathrm{k}$ represents the preference of customer of the chosen market for the design quality level of the specific product. Chen \& Chen, following the concept of Anderson and Sullivan (Anderson et al., 1993), suggest a concave down function of $\alpha$ as $\alpha=\delta^{\mathrm{k}}$ (7) as a quantitative approach for the determination of the parameter $\mathrm{k}$, where $\delta$ is the target customer satisfaction determined by management and $\alpha$ presents the target design quality level of a product. Alternatively, the management can define the value of $\mathrm{k}$ subjectively.

In this approach, the design quality level of a product is handled as the F-Fulfillment level and B-Fulfillment level of specific products that is depicted as following:

$$
\mathrm{DQ}_{\mathrm{F}, \mathrm{B}}(\mathrm{X})=1 / \mathrm{n}, \mathrm{z} \sum_{\mathrm{j}, \mathrm{g}=1}^{\mathrm{n}, \mathrm{z}} \mathrm{x}_{\mathrm{j}, \mathrm{g}}(8) ; 0<\mathrm{DQ}_{\mathrm{F}, \mathrm{B}}(\mathrm{X}) \leq 1
$$

Customer satisfaction (CS) is then described as a function of $\mathrm{F}$ or B, which is adjusted considering the equalities of Chen \& Chen as following:

$$
\mathrm{CS}_{\mathrm{F}, \mathrm{B}}(\mathrm{X})=\sum_{\mathrm{i}=1}^{\mathrm{m}} \mathrm{d}_{\mathrm{i}}^{\text {norm }} \sum_{\mathrm{j}, \mathrm{g}=1}^{\mathrm{n}, \mathrm{z}} \mathrm{R}_{\mathrm{ij}, \mathrm{ig}}^{\text {norm }} \mathrm{x}_{\mathrm{j}, \mathrm{g}}(9) ; 0 \leq \mathrm{x}_{\mathrm{j}, \mathrm{g}} \leq 1 ; 0<\mathrm{CS}_{\mathrm{F} / \mathrm{B}}(\mathrm{X}) \leq 1
$$

In order to show the relation between customer satisfaction and product quality level, different constraints have to be defined. First, the product overall design quality $\mathrm{DQ}_{\mathrm{F}, \mathrm{B}}(\mathrm{X})$ for each $\mathrm{F}$ and each $\mathrm{B}$ respectively should be greater equal than the target product quality level $\alpha$ as shown in $\mathrm{DQ}_{\mathrm{F}, \mathrm{B}}(\mathrm{X}) \geq \alpha$ (10). Then, the achieved customer satisfaction $\mathrm{CS}_{\mathrm{F}, \mathrm{B}}(\mathrm{X})$ based on the fulfillment level of Fs and Bs should be greater equal to the target customer satisfaction $\delta$ : $\mathrm{CS}_{\mathrm{F}, \mathrm{B}}(\mathrm{X}) \geq \delta(11)$. Based on concave down function (7), the next constraint is shown in the following inequation:

$$
\mathrm{DQ}_{\mathrm{F}, \mathrm{B}}(\mathrm{X})-\mathrm{CS}_{\mathrm{F}, \mathrm{B}}(\mathrm{X})^{\mathrm{k}} \geq 0 ; \mathrm{k}>1(12)
$$

which means that the fullfilled overall design quality should be greater than the quality level derived by the achieved customer satisfaction (Chen et al., 2014).

As next, there is a need for the definition of overall design quality level of DP (Fullfillment level of DP) that consists Fs and $\mathrm{Bs}\left(\mathrm{DQ}^{*}(\mathrm{X})\right)$. This is depicted in the following equation: 


$$
\mathrm{DQ}^{*}(\mathrm{X})=1 / \mathrm{p} \sum_{\mathrm{r}=1}^{\mathrm{p}} \mathrm{x}_{\mathrm{r}}+1 / \mathrm{q} \sum_{\mathrm{s}=1}^{\mathrm{q}} \mathrm{x}_{\mathrm{s}}
$$

where $\mathrm{X}_{\mathrm{r}}$ and $\mathrm{X}_{\mathrm{s}}$ represent the technical fullfillment level of DPs of $\mathrm{F}$ and B respectively with the consideration of the quality level of DP which is demanded to obtain the desired customer satisfaction.

\subsubsection{Normalized importance weights}

In order to find out in which way the different DP has an impact on customer satisfaction, the importance weight of each technical subsystem DP should be calculated. The first step is to define the importance weights $w_{j}^{\text {norm }}$ of $F$ and $w_{g}^{\text {norm }}$ of $B$. This equation is adapted considering the equation from Chen \& Chen study, the importance weight of design requirements. The relevant equation for F/B is depicted as following:

$$
\mathrm{w}_{\mathrm{j}, \mathrm{g}}^{\text {norm }}=\sum_{\mathrm{i}=1}^{\mathrm{m}} \mathrm{d}_{\mathrm{i}}^{\text {norm }} \cdot \mathrm{R}_{\mathrm{ij}, \mathrm{ig}}^{\text {norm }}(14)
$$

Considering the inequation (13), the next constraint is defined for both $\mathrm{F}$ and $\mathrm{B}$ respectively:

$$
\sum_{\mathrm{j}=1}^{\mathrm{n}} \mathrm{w}_{\mathrm{j}}^{\mathrm{norm}} \mathrm{x}_{\mathrm{j}} \geq \delta(15) \text { and } \sum_{\mathrm{g}=1}^{\mathrm{z}} \mathrm{w}_{\mathrm{g}}^{\mathrm{norm}} \mathrm{x}_{\mathrm{g}} \geq \delta(16)
$$

Finally the normalized importance weight of DPs of F and B respectively to the contribution of $\mathrm{CR}$ are defined as following:

$$
\mathrm{w}_{\mathrm{r}}^{\text {norm }}=\sum_{\mathrm{j}=1}^{\mathrm{n}} \mathrm{w}_{\mathrm{j}}^{\text {norm }} \cdot \mathrm{D}_{\mathrm{jr}}^{\text {norm }}(17), \quad \mathrm{w}_{\mathrm{s}}^{\text {norm }}=\sum_{\mathrm{g}=1}^{\mathrm{z}} \mathrm{w}_{\mathrm{g}}^{\text {norm }} \cdot \mathrm{D}_{\mathrm{gs}}^{\text {norm }}
$$

\subsubsection{Customer Satisfaction Function based on Importance weight of Design Parameter}

Now, the customer satisfaction function $\mathrm{CS}^{*}(\mathrm{X})$ based on importance weight of DP is defined under the consideration of (17) and (18):

$$
\mathrm{CS} *(\mathrm{X})=\sum_{\mathrm{r}=1}^{\mathrm{p}} \mathrm{w}_{\mathrm{r}}^{\text {norm }} \cdot \mathrm{x}_{\mathrm{r}}+\sum_{\mathrm{s}=1}^{\mathrm{q}} \mathrm{w}_{\mathrm{s}}^{\text {norm }} \cdot \mathrm{x}_{\mathrm{S}}
$$

with the following constraints $\sum_{\mathrm{r}=1}^{\mathrm{p}} \mathrm{w}_{\mathrm{r}}^{\text {norm }} \mathrm{x}_{\mathrm{r}} \geq \delta(20)$ and $\sum_{\mathrm{s}=1}^{\mathrm{q}} \mathrm{w}_{\mathrm{s}}^{\text {norm }} \mathrm{x}_{\mathrm{s}} \geq \delta(21)$.

\section{Application}

The goal of this section is to illustrate one industrial application, which demonstrates the proposed approach by evaluating real customer feedback of an existing reference product, deriving CR and executing the customer satisfaction function with the importance weight of each DP. These activies are performed in the scope of PGE. A comprehensive validation of the mathematical model is still in process.

For this application the customer feedback are taken from an empirical survey which are based on real feedback and is carried out for one specific vehicle Product $G_{n}$ (reference product of generation $n$ ), which is specific for the market USA. The implementation of the survey is conducted 3 months after purchasing the new vehicle of the Product $G_{n}$ by customers. Another possibility to contact customers again could not be carried out since the feedback from this empirical survey are anonym. This empirical study consists of 1013 feedback for the Product $\mathrm{G}_{\mathrm{n}}$. These Feedback present the responses of open questionnaires.

These customer feedback are assigned to the appropriate categories considering their content, in order to determine the relevant product development information. In addition, feedback are 
mapped to the $\mathrm{CF}$ and to their sub-CF. In this example, "Infotainment" $\left(\mathrm{CF}_{1}\right)$ that includes 143 customer feedback is now related to the relevant sub-CF, such as Navigation, Bluetooth, etc. Afterwards, feedback sets are generated for individual product components/Functions. In this application, resulting set of feedback comprises the feedback considering needs and approval from three categories: affective declaration, function related statement and extra, as shown in Table 1. The data from all steps are then mapped together, in order to derive 3 CRs of „Bluetooth“ (considering 62 Customer Feedback), as listed in Table 2. These CRs are relevant for the following three functions: $\mathrm{F}_{1}$ „Media“, $\mathrm{F}_{2}$ „Speed“ and $\mathrm{F}_{3}$ „Stability“. Considering the completed model (M), these functions are assigned to following DPs: $\mathrm{DP}_{1}, \mathrm{DP}_{2}, \mathrm{DP}_{3}$. The results of the customer evaluation are already discussed with the developers in an automotive company. These will be considered in the product development of this relevant specific product. For the development of a new product generation $\mathrm{G}_{\mathrm{n}+1}$, the mathematical model is applied for these CRs, Fs and DPs, where target customer satisfaction $\delta=0,9$ is determined by management in industrial practice. Due to the cooperation between the departments in industrial practice, the parameter $\mathrm{k}$ is determined with the value of 2 . With the help of the concave down function (7), the target design quality $\alpha=0.81$ is then determined.

Table 1: Determination of product information through categorization of customer feedback (FB)

\begin{tabular}{|c|c|c|c|c|c|c|c|}
\hline \multirow{2}{*}{$\begin{array}{l}\text { FB } \\
\text { ID }\end{array}$} & \multirow[t]{2}{*}{$\mathrm{CF}$} & \multirow{2}{*}{$\begin{array}{c}\text { Sub- } \\
\text { CF }\end{array}$} & \multicolumn{2}{|c|}{ Affective Declaration } & \multicolumn{2}{|c|}{ Function Related Statement } & \multirow[t]{2}{*}{ Extra } \\
\hline & & & appeal & approval & appeal & approval & \\
\hline 42 & \multirow{8}{*}{ 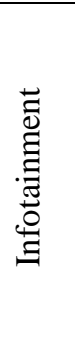 } & \multirow{8}{*}{ 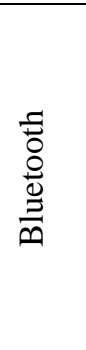 } & & & can't use & & with siri \\
\hline 47 & & & & & no allow & & for google maps \\
\hline 54 & & & & & delays & & music \\
\hline 79 & & & long & & delay & & media devices \\
\hline 82 & & & & & skipping & & desired song \\
\hline 91 & & & & & rewinding & & Begin of song \\
\hline 94 & & & & flawlessly & & Works & \\
\hline 98 & & & $\ldots$ & & $\ldots$ & & $\ldots$ \\
\hline
\end{tabular}

Table 2 : Derived Customer Requirements for the sub-CF "Bluetooth"

\begin{tabular}{|l|l|}
\hline CR1 & Usage possibility with media (e.g. Google Maps) \\
\hline CR2 & No delays and skipping by media devices \\
\hline CR3 & No rewinding by media \\
\hline
\end{tabular}

Through the usage of formulas (1), (3) and (4), the relational intensity ( $\mathrm{R}_{\mathrm{ij}}^{\text {norm }}$ ) between all three CRs and related $F s, d_{i}^{\text {norm }}$ the normalized importance weight of each $C R, D_{j r}^{\text {norm }}$ the relational intensity between Fs and related DPs are determined. For that, degree of importance weight of CRs $\left(\mathrm{d}_{\mathrm{i}}\right)$ is considered, which is based on number of customer feedback. Consequently the importance weight $w_{j}^{\text {norm }}$ of $F$ (Formula (14)) is determined. Lastly, the calculation of (17) is executed, in order to determine the normalized importance weight $\mathrm{w}_{\mathrm{r}}$ norm of each DP to the contribution of all relevant CRs considering all relevant Fs. The results are summarized in Figure 2 for the three defined CRs, Fs and DPs. 


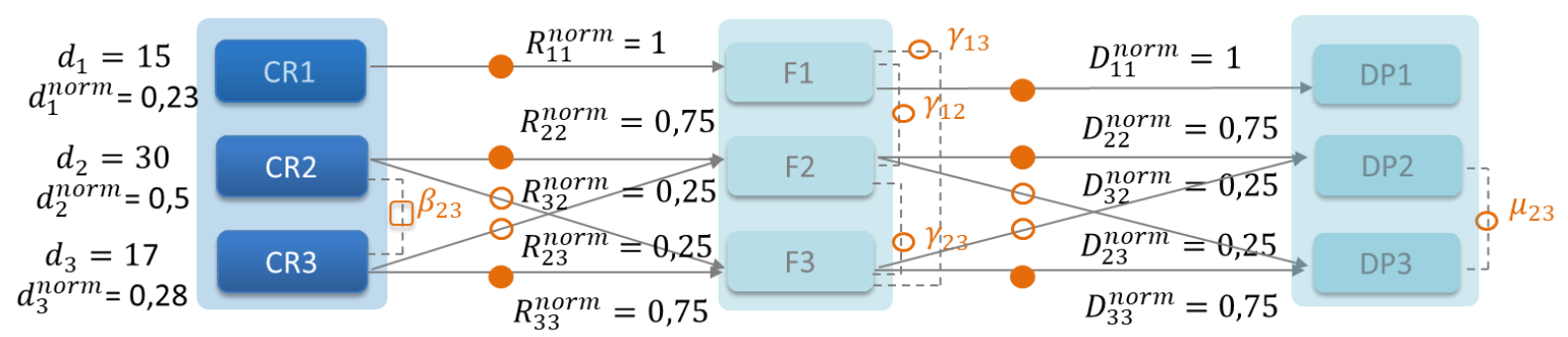

Correlation (C) within $\mathrm{CR}, \mathrm{F}$ and $\mathrm{DP}$ and

Relations ( $R$ ) between $C R, F$ and DP

Symbols with Values:

Strong: 0,9 (C); 9 (R)

O Moderate: $0,3(C) ; 3(R)$

Weak : $0,1(C) ; 1(R)$

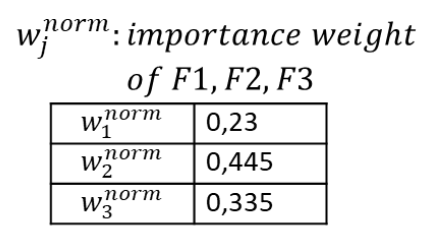

$w_{r}^{\text {norm }}$ : importance weight
of $D P 1, D P 2, D P 3$
\begin{tabular}{|l|l|}
\hline$w_{1}^{\text {norm }}$ & 0,23 \\
\hline$w_{2}^{\text {norm }}$ & 0,41 \\
\hline$w_{3}^{\text {norm }}$ & 0,36 \\
\hline
\end{tabular}

Figure 2. Product Model M showing the relation between customer feedback and the importance weights of DP for the application

Consequently, Customer satisfaction function CS* $(\mathrm{X})$ for sub-CF „Bluetooth“ of product $\mathrm{Gn}$ is presented using the equation (20) considering the importance weight $\mathrm{w}_{\mathrm{r}}^{\text {norm }}$ of each design parameter DP: $0,23 \cdot x_{1}+0,41 \cdot x_{2}+0,36 \cdot x_{3} \geq 0,9$. This constraint should be fulfilled in order to verify if the target customer satisfaction $(\delta=0,9)$ is reached.

As next, the constraint fullfilled design quality level $\mathrm{DQ}^{*}(\mathrm{X})$ for all relevant Fs is described using the equation (13) and the inequation in (10): $x_{1}+x_{2}+x_{3} \geq 3 \times 0,81$. This constraint shows that the average of the technical fullfillment levels of DPs should be greater than the target fullfilled quality level $\alpha(0,81)$. In order to determine the values of $\mathrm{x}$, further equations regarding the minimum required satisfaction level for all CRs and the minimum fullfilled quality level for all DPs have to be considered taking into account the budgetary limitation during the development activities (Chen, Chen et al., 2014).

\section{Conclusion and Future Work}

Empirical surveys give customers the chance to express their opinion. However, the integration of particularly uniformalised opinions/feedback as input into the product development activities is quite challenging and information loss and misinterpretation during the evaluation can occur. In addition, development of new products through the systematic variation of technical subsystems over generation, which is supported by PGE, can increase of customer satisfaction with the product. However, a systematic approach does not exist, which shows how the customer satisfaction is reached up to a very detailed level of subsystems, such as design parameter.

To alleviate such problems, approaches in literature were analysed and a need for the identification of different information types could be worked out. Moreover the customer satisfaction and its relation to the technical subsystems, supported by PGE, is worked out as well. Nevertheless, the PGE model does not introduce the integration of customer feedback into the relevant process. In addition, the other analysed literature do not consider PGE by showing the relation between customer satisfaction and technical subsystem and by evaluation of customer feedback. The present publication makes a contribution to the identification of relevant product development information with the help of categorization. The defined categories prevent information loss and misinterpretation during the evaluation. They also support to differentiate and to filter several kind of product development relevant information. $\mathrm{CF}$ and sub-CF are used to define the domain of the relevant products. During a synthesis, the 
determined information from categorization are brought together with these factors in order to derive customer requirements of corresponding sub-CF. Furthermore, a mathematical model is prepared to provide the identification of the importance weight of each DP. These all are executed in the context of product model of PGE, where the levels of this model are completed up to the level of technical subsystem design parameter.

As demonstration, the evaluation of customer feedback from an empirical study is showcased with the real customer feedback. Its results are illustrated in Table 1, where the categorized information are shown. In addition, Table 2 illustrates the derived customer requirements which are discussed with the developers from an automotive company for a further usage in the product development. Moreover, through the application of a mathematical model, the importance weight of each DP is determined, which have an impact on customer satisfaction. A comprehensive validation of the mathematical model is still in process.

In future research the software support for the presented approach will be elaborated. The implementation of model M (s. Figure 1 above) based on Model-based Systems Engineering (SE) for a complete vehicle and for other product types is still pending in a collaboration with the development department in an automotive company and will be examined next to transfer the qualitative customer feedback into DP. A Model-based SE supports the documentation of various development activities and their results in a central common system model. In additon, it supports context based views of relationsships (Inkermann et al., 2019). For the application of the mathematical model, an appropriate software support is still in discussion. The implementation of the mathematical results are going to be conducted with the developers in an automotive company as well.

\section{Citations and References}

Albers, A., Bursac, N., Wintergerst, E. (2015). Produktgenerationsentwicklung - Bedeutung und Herausforderungen aus einer entwicklungsmethodischen Perspektive. Stuttgarter Symposium für Produktentwicklung, Stuttgart.

Albers, A., Dumitrescu, R., Marthaler, F., Kühfuss, D., Albers, A.A., Strauch, M., Siebe, A., Bursac, N. (2018). PGE - Produktgenerationsentwciklung und Zukunftvorausschau: Eine systematische Betrachtung zur Ermittlung der Zusammenhänge PGE. Symposium für Vorausschau und Technologieplanung, Berlin.

Albers, A., Basedow, G.N., Bursac, N., Heimicke, J., Heitger, N., Reiss, N., Ott, S., Walter, B. (2018). Product Profiles: Modelling customer benefits as a foundation to bring inventions to innovations. 28th CIRP Design Conference, Nantes.

Albers, A., Eichhorn, P., Moeser, G., Rapp, S. (2018). Identifying Expedient Variations in PGE - Product Generation Engineering. Nord Design Conference, August 14-17, Linköping.

Albers, A., Haug, F., Fahl, J., Hirschter, T., Reinemann, J., Rapp, S. (2018). Customer Oriented Product Development: Supporting the Development of the Complete Vehicle through the Systematic Use of Engineering Generations, IEEE International System Engineerings Symposium (ISSE), Rome.

Albers, A., Bursac, N., Fahl, J., Haug, F., Heitger, T., Hirschter, T. (2018). Supporting potential innovation in the early phase of PGE - Product Generation Engineering: Structuring the development of the initial System of Objectives. R\&D Management Conference, in press, Milan.

Albers, A., Fahl, J., Haug, F., Heitger, N., Hirschter, T. (2019). Engineering Generations to Control Product Generation Engineering: From Component to Function Orientation in Automotive Development. Stuttgarter Symposium für Produktentwicklung, Stuttgart.

Anderson, E. W. \& Sullivan, W. (1993). The andecedents and consequences of customer satisfaction for firms. Marketing Science, Vol. 12m, no.2, pp. 125-143. 
Chen, L.-H. \& Chen, C.-N. (2014). A QFD based Mathematical Model for New Product Development considering the Target Market Segment. Journal of applied Mathematics, Hindawi Publishing Corporation.

Halender, M., Khalid, H.M. (2012). Affective and pleasurable Design. In: Salvendy, G. Wiley, Handbook of Human Factros and Ergonomics, pp.569-571, New York.

Inkermann, D., Huth, T., Vietor, T., Grewe, A., Knieke, C., Rausch, A. (2019). Model-Based Requirement Engineering to Support Development of Complex Systems. 29th CIRP Design, Póvoa de Varzim.

Ishikawa, K. (1993). Introduction to Quality Control. 3A Corporation, Tokyo.

DIN EN ISO 9000 (2015). Quality Management Systems - Fundamentals and Vocabulary.

Li, S., Tang, D., Wang, Q. (2019). Rating Engineering Characteristics in open design using a probabilistic language method based on fuzzy QFD. Elsevier Computers and Industrial Engineering. Vol. 135, pp. 348-358.

Muffato, M. \& Panizollo, R. (1995). A process-based view for customer satisfaction. International Journal of Quality \& Reliability Management. Vol. 12, no.9, pp. 154-169.

Nehuis, F. (2014). Methodische Unterstützung bei der Ermittlung von Anforderungen in der Produktentwicklung, Dissertation. Vol. 86, Verlag Dr. Hut, München.

Pahl, G. and Beitz W. Feldhusen, J., Grote, K.-H (2007). Engineering Design: A Systematic Approach, Springer, Berlin-Heidelberg.

Park, Y., Lee, S. (2018). How to design and utilize online customer center to support new product concept generation in Measuring design-level information quality in online reviews. Expert Systems with Applications, Vol.38, no.8.

Rai, R. (2012). Identifying Key Product Attributes and their Importance Levels from Online Customer Reviews. ASME International Design Engineering Technical Conferences \& Computers and Information in Engineering, pp. 533-540, August 12-15, Chicago.

Schulte, S. (2006). Integration von Kundenfeedback in die Produktentwicklung zur Optimierung der Kundenzufriedenheit. Dissertation, Bochum.

Schütte, S. (2005). Engineering Emotional Values in Product Design, Dissertation, Linköpings Universitet, Linköpings.

Schütte, S., Krus, P. (2008). Integration of Affective Engineering in Product Development Process. 11th QMOD Conference, 20-22 August, Helsinborg.

Stechmann, L. (2011). Potenziale zur Steigerung der Kundenzufriendenheit mit Automobilwerkstätten. Dissertation, Berlin.

Vajna, S., Weber, C., Bley, H., Zeman, C. (2009). CAx für Ingenieure: Eine praxisbezogene Einführung, 2nd ed., Springer, Berlin-Heidelberg.

Urban, G.L., Hauser, J.R. (1993). Design and Marketing of New Products. Prentice-Hall, New Jersey.

Wang, Y., Mo, D., Tseng, M.M. (2018). Mapping Customer Needs to Design Parameters in the Front End Product Design by Applying Deep Learning. Analysis Manufactoring Technology, Vol. 67, no.1.

Wang, W.M., Li, Z., Tian, Z.G., Wang, J.W., Cheng, M.N. (2018). Extracting and summarizing affective features and responses from online product descriptions and reviews: A Kansei text mining approach. Engineering Applications of Artifical Intelligence, Vol.73.

Yagci, I., Das, S. (2018). Measuring design-level information quality in online reviews. Electronic Commerce Research Applications, Vol. 73, no. 30. 